\title{
A Global Evolutionary Trend of the Frequency of Primary Glomerulonephritis over the Past Four Decades
}

\author{
Keng Thye $\mathrm{Woo}^{\mathrm{a}}$ Choong Meng Chan $^{\mathrm{a}}$ Cynthia Lim $^{\mathrm{a}}$ Jason Choo ${ }^{\mathrm{a}}$ \\ Yok Mooi Chin ${ }^{a}$ Esther Wei Ling Teng ${ }^{\text {a }}$ Irene Mok ${ }^{a}$ Jia Liang Kwek ${ }^{a}$ \\ Alwin H.L. Loh ${ }^{c}$ Hui Lin Choong ${ }^{a}$ Han Kim Tan $^{a}$ Grace S.L. Lee $^{a}$ Evan Lee $^{b}$ \\ Kok Seng Wong ${ }^{\text {a }}$ Puay Hoon Tan ${ }^{c}$ Marjorie Foo ${ }^{a}$ \\ ${ }^{a}$ Department of Renal Medicine, Singapore General Hospital, Singapore, Singapore; ${ }^{b}$ Department of Renal \\ Medicine, National University of Singapore, Singapore, Singapore; ${ }^{C}$ Department of Pathology, Singapore General \\ Hospital, Singapore, Singapore
}

\section{Keywords}

Clinical epidemiology - Focal segmental glomerulosclerosis . Glomerulonephritis · IgA nephritis · Diabetic nephropathy ·

Renal biopsy

\begin{abstract}
Objective: The pattern of glomerulonephritis (GN) in Singapore is compared with that of 19 other countries to review changing trends in the evolution of GN in Asian, Eastern, and Western countries. Method: Three thousand two hundred and eighty-nine renal biopsies in Singapore were reviewed and compared with that of 19 other countries. Results: IgA nephritis is on the decline in many countries, including Singapore, though it still remains the commonest GN in Singapore. Membranous GN that if used to be more frequently present in Western countries has also declined though it continues a rising trend in countries such as Singapore and China. Worldwide, the frequency of focal sclerosing glomerulosclerosis (FSGS) continues to increase in many countries, but in some countries, the frequency is still low with mesangiocapillary GN remaining indigenous. Conclusion: Urbanization and socioeconomic changes and less exposure to
\end{abstract}

\section{KARGER}

(c) 2019 S. Karger AG, Basel

E-Mail karger@karger.com

www.karger.com/kdd parasitic and other infestations have transformed Singapore's pattern, which is tending toward that of more developed countries. Antigenic exposure due to lifestyle changes, environmental, and industrial pollution are significant contributory factors that affect the evolutionary trend of GN in many countries. The rising trend in the frequency of FSGS may reflect aging and obesity.

(c) 2019 S. Karger AG, Basel

\section{Introduction}

Glomerular disease still remains a leading cause of end-stage renal failure worldwide. We undertake this review because we believe that an understanding of the changing pattern of glomerulonephritis (GN) worldwide will enable us to use such epidemiological data to help plan for better patient care and disease prevention. One such important study is the review on changing spectrum of kidney diseases by Hou et al. [1] from the National Clinical Research Centre of Kidney Diseases in Jinling Hospital in Nanjing with a large database of cases that compare renal biopsies done in 2 periods from 1979 to

Professor Keng-Thye Woo

Department of Renal Medicine, Singapore General Hospital Outram Road

Singapore 169608 (Singapore)

E-Mail woo.keng.thye@sgh.com.sg 
2002 (13,519 biopsies) and from 2003 to 2014 (40,759 biopsies). One of their key findings was that the rising frequency of membranous GN between these 2 periods could be related to industrialization and environmental pollution.

Another lesson is from a large Italian Registry by Zaza et al. [2] involving 4,378 adult patients where 1,185 or $27 \%$ of the biopsied patients have chronic renal failure. Their study revealed that even in patients with eGFR $<30 \mathrm{mLs} /$ min it was possible to perform an accurate histological diagnosis that enabled specific therapies in about $40 \%$.

This present review is a longitudinal study spanning 4 decades where we compared our data with that of the international community to observe various periods where significant or pivotal changes have occurred throughout these periods and enable us to correlate such changes with environmental or other socioeconomic factors that have impacted and caused the pattern of GN to undergo evolution in these countries. Three main factors, geographical or environmental, socioeconomic, and genetic factors are the common agents of changes and varying measures of such factors would affect the distribution of both primary and secondary GN in various countries.

We had previously reported the changing pattern of primary GN over 3 decades in Singapore and various countries and as such countries improve with better socioeconomic circumstances, the renal biopsy pattern has changed accordingly. But now after evolving for 30 years, with data from the 4 th decade, we evaluate if the present digital age with the accompanying rapidly changing circumstances would have a further impact on the present evolutionary pattern of GN worldwide.

\section{Objectives}

In this review, with data for the 4th decade, we can compare the changing trends in mesangial proliferative $\mathrm{GN}$, IgA nephritis (IgA Nx), membranous GN, and focal and segmental glomerulosclerosis (FSGS), and in particular, evaluate whether the overall trend is in keeping with that observed in the Asian countries and the more developed Western countries, especially with regard to FSGS, which is fast becoming a very common form of GN among the developed nations [3].

\section{Materials and Methods}

\section{Renal Biopsy Registry}

This is a retrospective study over 40 years on the evolving pattern of primary GN in a population not affected by any significant immigration or change in racial make-up over the first 30 years, though in the past 10 years, a limited immigration has occurred to offset the decreasing birth rate in the country, but this has not made any significant impact on the racial makeup of the past decade. A Renal Biopsy Registry was established 40 years ago. We have documented 4 decades of changes over the 1st, 2nd, 3rd, and 4th decades (1978-1988, 1988-1998, 1998-2008, 2008-2018).

Toward the middle of the 1st decade, with the opening of the National University Hospital in 1985 , about $15 \%$ of the renal biopsies were performed there, and the bulk $85 \%$ still performed at Singapore General Hospital (SGH) the main hospital. In the middle of the 3rd decade, 2003, a third renal unit was established in Tan Tock Seng Hospital, which biopsied about $10 \%$ of patients. In the 4 th decade, during the past 3 years, another hospital has been opened, the Khoo Teck Puat Hospital, which biopsied 3\% of the patients. So, throughout the 4 decades, the market share of the patient load in SGH has decreased and now continues to do about $70 \%$ of the biopsies. SGH is the oldest and the flagship hospital in the small city state and still serves as the main tertiary referral hospital.

The indications for renal biopsy were any one or more of the following in the 1st decade:

- Proteinuria of $>0.2$ g or more

- Urine RBC persistently $>20$ per high-power field.

- Gross hematuria on follow-up associated with proteinuria of $>0.2$ g or more.

- Presence of abnormal renal function or hypertension.

In the 2 nd and 3 rd decades, the indications for renal biopsy were modified as our analysis of the biopsies in the 1st decade had shown that patients with very mild microscopic hematuria $(<100$ per high-power field) and mild proteinuria $(<1 \mathrm{~g} /$ day $)$ were found to have mild glomerular lesions with no significant glomerulosclerosis.

Therefore, for the 2nd, 3rd, and 4th decades, the indications for renal biopsy was any one or more of the following:

- Proteinuria of $1 \mathrm{~g}$ or more.

- Urine RBC persistently >100 per high-power field.

- Gross hematuria on follow-up associated with proteinuria of $1 \mathrm{~g}$ or more.

- Presence of abnormal renal function or hypertension.

These indications have since not changed over the past 3 decades, but the change in biopsy policy from the 2 nd decade onward accounted for the decreased number of biopsies done in the $2 \mathrm{nd}$, $3 \mathrm{rd}$, and 4 th decades.

The Classification of GN (World Health Organization, Collaborating Centre for the Histological Classification of Renal Diseases) used in this paper is similar to that adopted by Renal Biopsy Registries worldwide, and this has not changed significantly during the past 4 decades and will allow ease of comparison of biopsy data among various countries [4].

\section{Renal Biopsy Data Collection from Other Countries}

These are the latest data in the various papers from these countries, incorporating as much data as we can from the original publications in Nephrology Journals during the past 40 years.

(i) Choice of the 4 sets with data that spanned longest period (years) so as to show changes over past 4 decades over a long period as in the case of Australia and the United States.

(ii) To strive to preserve a continuum of time frame over the past 2-4 decades and also incorporate the latest data from a particular country as in the case of United States where we included 
Table 1. Primary GN: demographics over 4 decades

\begin{tabular}{lllll}
\hline & 1st decade (D1) & 2nd decade (D2) & 3rd decade (D3) & 4th decade (D4) \\
\hline Gender (male:female) & $2.4: 1$ & $1.2: 1$ & $1.4: 1$ & $1: 1$ \\
Mean age, years (range) & $26.4 \pm 10.0(15-71)$ & $32.4 \pm 10.8(15-79)$ & $39.4 \pm 13.6(15-80)$ & $47.9 \pm 13.5(15-85)$ \\
Prevalence of obesity, BMI $\geq 30 \mathrm{~kg} / \mathrm{m}^{2}, \%$ & NA & 5.1 & 6.9 & 10.8 \\
Prevalence of diabetes, $\%$ & 4.7 & NA & 9.0 & 11.3 \\
\hline
\end{tabular}

GN, glomerulonephritis; NA, not applicable.

Table 2. Primary GN: clinical presentation over 4 decades

\begin{tabular}{lcccccc}
\hline Clinical presentation & $\begin{array}{l}\text { 1st decade } \\
(\mathrm{D} 1), n(\%)\end{array}$ & $\begin{array}{c}\text { 2nd decade } \\
(\mathrm{D} 2), n(\%)\end{array}$ & $\begin{array}{l}\text { 3rd decade } \\
(\mathrm{D} 3), n(\%)\end{array}$ & $\begin{array}{l}\text { 4th decade } \\
(\mathrm{D} 4)\end{array}$ & $\begin{array}{c}p\left(\chi^{2}\right) \\
\text { D3 vs. D4 }\end{array}$ & $\begin{array}{c}p\left(\chi^{2}\right) \\
\text { D1 vs. D2 vs. } \\
\text { D3 vs. D4 }\end{array}$ \\
\hline Hematuria and proteinuria & $569(50)$ & $236(35)$ & $240(30)$ & $95(13)$ & $<0.00001$ & $<0.00001$ \\
Gross hematuria & $98(9)$ & $26(4)$ & $12(2)$ & $9(1)$ & 0.68718 & $<0.00001$ \\
Nephrotic syndrome & $363(32)$ & $238(36)$ & $357(45)$ & $313(45)$ & 0.72852 & $<0.00001$ \\
Acute nephritis & $11(1)$ & $44(7)$ & $14(2)$ & $43(6)$ & 0.000013 & $<0.00001$ \\
Chronic renal failure & $30(3)$ & $3(<1)$ & $55(7)$ & $93(13)$ & 0.00006 & $<0.00001$ \\
Hypertension & $47(4)$ & $93(14)$ & $94(12)$ & $131(19)$ & 0.00033 & $<0.00001$ \\
Others & $9(1)$ & $26(4)$ & $14(2)$ & $19(3)$ & 0.22785 & 0.000074 \\
\hline Total & $1,127(100)$ & $666(100)$ & $786(100)$ & $703(100)$ &
\end{tabular}

GN, glomerulonephritis.

Sim et al. [5] study (2000-2011), rather than Arias et al. [6] (19982007). France as in Simon et al. [7] study (1976-2002) and Italy's data from Zaza et al. [2] (1998-2010) were chosen to preserve the continuum as well as the latest data from that country.

(iii) Where the data were out of sync and inconsistent with a particular trend, we chose not to include it in the figures.

\section{Statistics}

Chi-square test (with Yate's correction) for $2 \times 3$ table of frequency counts were used to determine the significance of differences between data from the 1st, 2 nd, and 3rd decades (D1 vs. D2 vs. D3). For differences between the $3 \mathrm{rd}$ and 4 th decades (D3 vs. D4), $2 \times 2$ frequency counts were used.

\section{Results}

\section{Demographics of Patients}

Table 1 on the demographics of the patients shows the number of patients with primary and secondary GN, gender, age, prevalence of obesity and diabetes, and per capita income. The mean age of the biopsied patients was $47.9 \pm 13.5$ years with a range from 15 to 85 years. Overall, the age of the biopsied patients has further increased, and this is consistent with the aging population. The data show an increasing trend for obesity, diabetes, as well as rising per capita income in the population.

\section{Clinical Presentation}

Table 2 shows the clinical presentation and distribution of the various types of primary GN in the 4 decades. The commonest clinical presentation in the 1st decade was asymptomatic hematuria and proteinuria. For the 2nd, 3rd, and 4th decades, nephrotic syndrome was the commonest with the proportion of nephrotic syndrome being more preponderant in the 3 rd decade (36\% in the 2 nd decade versus $45 \%$ in the 3 rd decade as well as in the 4 th decade, $[p<0.00001])$. Gross hematuria as a presenting feature was much less in the 4 th decade compared to the 1 st 3 decades ( 1 vs. $2 \%, 4$ and $9 \%$ in the 3 rd, 2 nd, and 1 st decade; $p<0.00001)$. Patients presenting with chronic renal failure had increased significantly in the 4 th decade, $13 \%$ compared to 7,1 , and $3 \%$ in the $3 \mathrm{rd}, 2 \mathrm{nd}$, and 1 st decades $(p<0.00001)$. 
Table 3. Primary GN: histological presentation over 4 decades

\begin{tabular}{|c|c|c|c|c|c|c|c|}
\hline & Histology & $\begin{array}{l}1 \text { st decade } \\
\text { (D1), } n(\%)\end{array}$ & $\begin{array}{l}\text { 2nd decade } \\
\text { (D2), } n(\%)\end{array}$ & $\begin{array}{l}\text { 3rd decade } \\
\text { (D3), } n(\%)\end{array}$ & $\begin{array}{l}4 \text { th decade } \\
\text { (D4), } n(\%)\end{array}$ & $\begin{array}{l}p\left(\chi^{2}\right) \\
\text { D1 vs. D2 vs. } \\
\text { D3 vs. D4 }\end{array}$ & $\begin{array}{l}p\left(\chi^{2}\right) \\
\text { D3 vs. D4 }\end{array}$ \\
\hline 1 & Minimal change & $97(9)$ & $87(13)$ & $151(19)$ & $141(20)$ & $<0.00001$ & 0.68157 \\
\hline 2 & Focal global sclerosis & $72(6)$ & $83(12)$ & $31(4)$ & $7(1)$ & $<0.00001$ & 0.00031 \\
\hline 3 & Mesangial proliferative GN & $357(32)$ & $112(17)$ & $55(7)$ & $26(4)$ & $<0.00001$ & 0.00507 \\
\hline 6 & Membranous GN & $38(3)$ & $42(6)$ & $90(11)$ & $102(15)$ & $<0.00001$ & 0.0787 \\
\hline 7 & Crescenteric GN & $5(1)$ & $1(1)$ & $8(1)$ & $20(3)$ & $<0.00001$ & 0.00956 \\
\hline \multirow[t]{2}{*}{8} & Others & $28(2)$ & 0 & $20(3)$ & $39(5)$ & NA & 0.00302 \\
\hline & Total & $1,127(100)$ & $666(100)$ & $786(100)$ & $703(100)$ & & \\
\hline
\end{tabular}

FSGS, focal and segmental glomerulosclerosis; GN, glomerulonephritis; IgA Nx, IgA nephritis; NA, not applicable.

\section{Renal Biopsy Data from Singapore}

Table 3 shows that the commonest histopathological diagnosis was IgA Nx, $42 \%$ in the 1 st decade, $45 \%$ in the 2 nd decade, and $40 \%$ in the 3 rd decade, but in the 4 th decade, it has decreased to $27 \%$. Mesangial proliferative GN (Non IgA) was the second commonest cause of primary GN in the 1 st decade (32\%) but has steadily declined to $17 \%$ in the 2 nd decade, $7 \%$ in the 2 rd decade $(p<0.000001)$, and in the 4 th decade only $4 \%(p<0.00001)$. This decrease in the 4th decade of mesangial proliferative GN was accompanied by a significant increase in minimal change $(p<0.00001)$, FSGS $(p<0.00001)$, and membranous GN $(p<0.00001)$ compared to the 1st, 2nd, and 3rd decades. In both FSGS and membranous GN in the 4 th decade, there was a significant increase compared to the 3rd decade. Crescenteric GN, though uncommon, had increased from 1 to $3 \%(p<0.00956)$ between the 3 rd and 4 th decades.

\section{Comparison Among International Data}

Table 4 presents renal biopsy data from 20 countries worldwide, and in 18 countries there are available data to enable readers to study the pattern of renal biopsies between 2 periods, at the beginning and about 40 years later to allow a comparison of the data in the individual country as well as comparison with other countries. It provides an analysis of evolving trends among the various countries and the surrounding regions. The data also show the common features in histological profile among Asian countries in contrast to others in the East as well as the West. We have presented a comprehensive table and have incorporated as much data as we can from the original publications in Nephrology Journals during the past 40 years. Based on data in the various papers from different countries, we have focused on the various primary GN, removing secondary GN (such as lupus nephritis and diabetic nephropathy) from the total numbers biopsied in order to obtain comparable data for various types of primary GN. Most countries had included IgA Nx as a separate group of primary GN. All the other mesangial proliferative GN that were non-IgA Nx were classified as mesangial proliferative GN. A few countries, however, grouped IgA Nx under mesangial proliferative GN in the initial years, but subsequently in later years also had separate categories for IgA $\mathrm{Nx}$ and mesangial proliferative GN. These countries also have a high prevalence of IgA $\mathrm{Nx}$ and are mainly in the Asian region.

Some countries have a separate group classified under mesangiocapillary glomerulonephritis (MCGN) as it is still prevalent in their population, while other countries have very few patients with MCGN, such as Singapore $(<1 \%)$, and have included them under "Others." Where MCGN is separately classified as MCGN, we have included this as a separate heading named MCGN. Those countries with high frequency of MCGN usually have low frequency of mesangial proliferative GN. Both MCGN and mesangial proliferative GN are related to infections. Post infectious GN or diffuse endocapillary GN is very uncommon in many countries and their biopsy registries do not classify such biopsies as a separate group and in the few that do so we have included these under "Others" as well. As far as possible, we have strived toward the presentation of data, which would enable us to make appropriate comparisons for the distribution of primary GN among the various countries. 


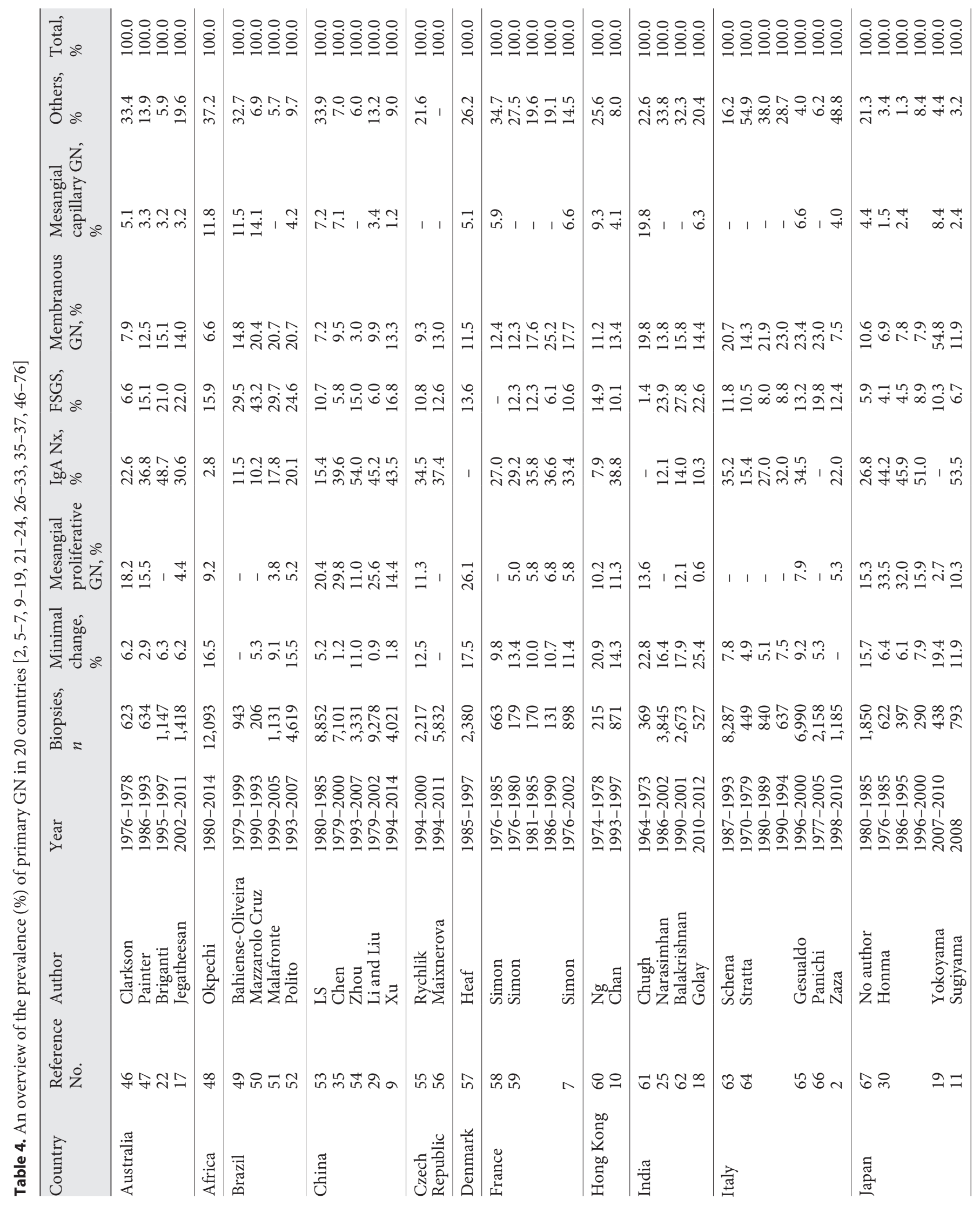




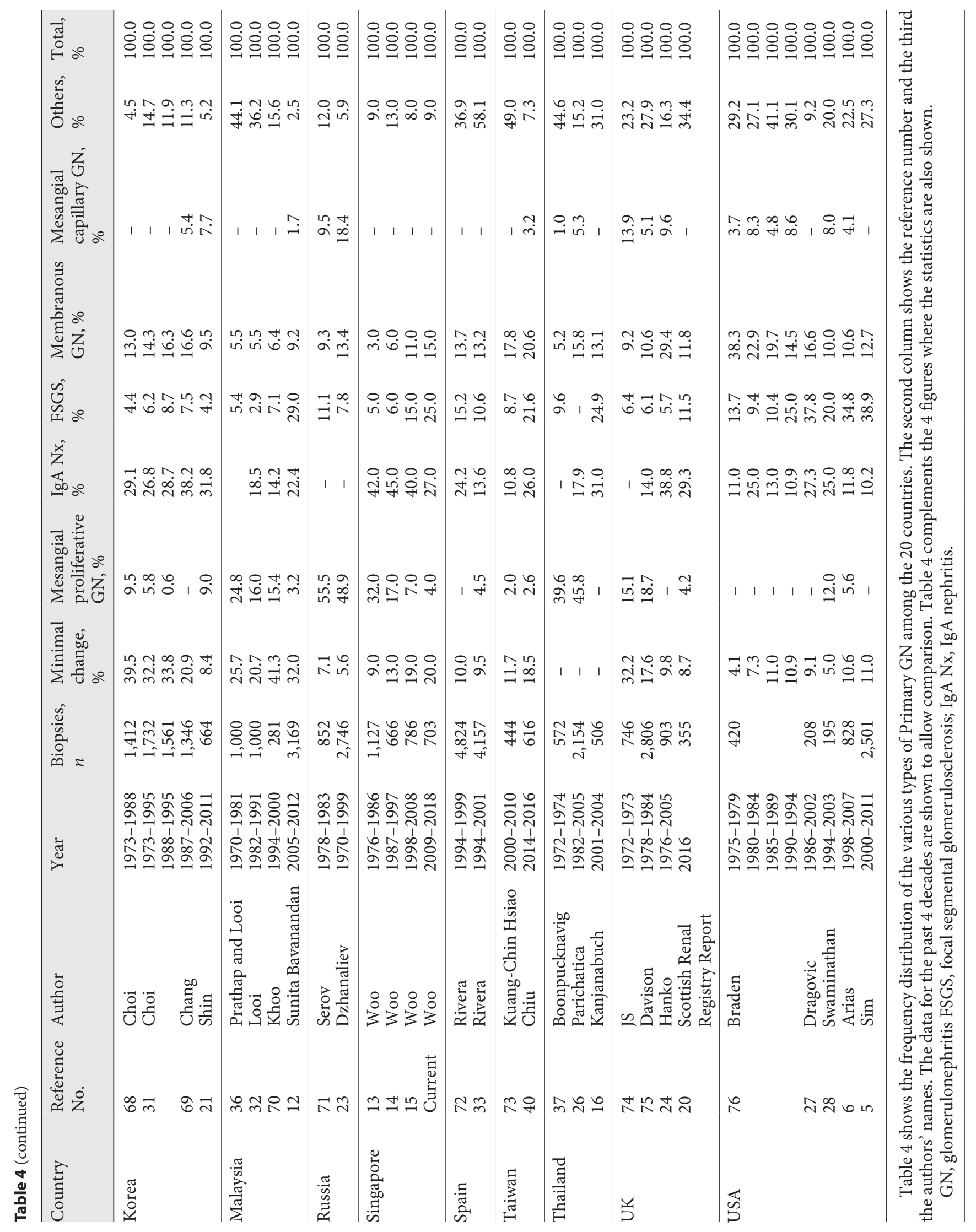




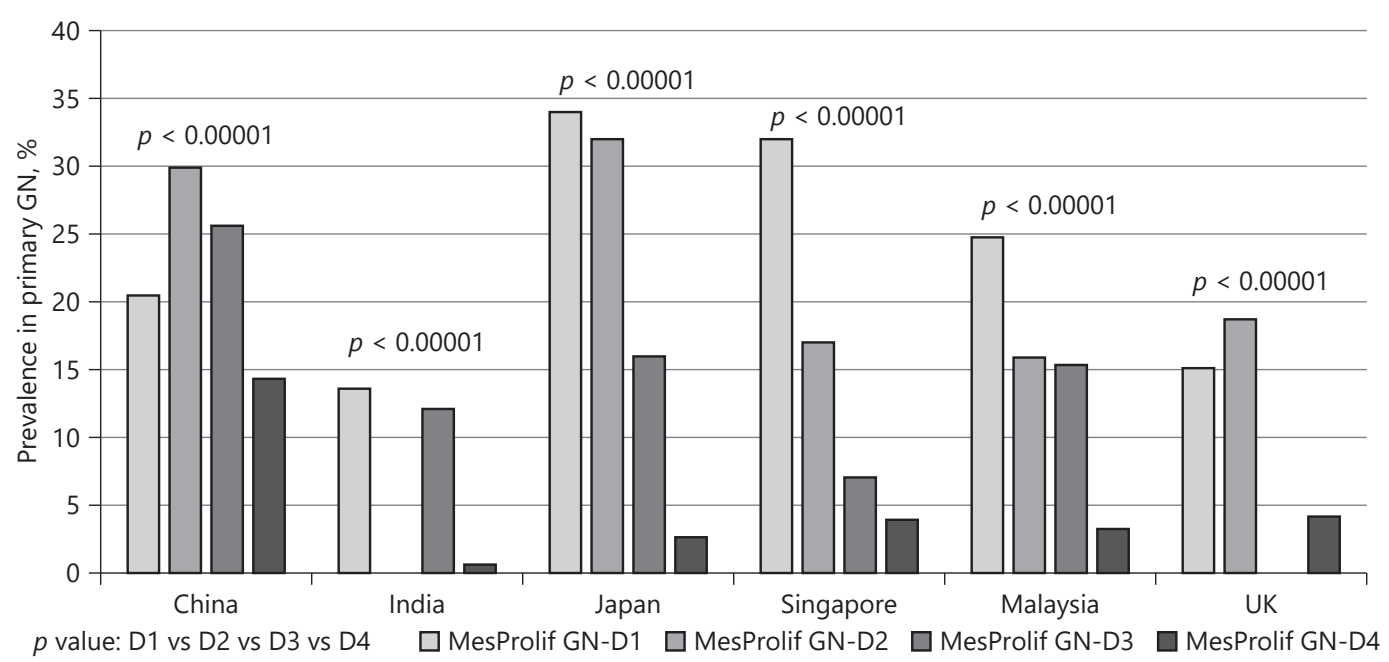

Fig. 1. Countries with decreasing trends for mesangial proliferative GN (Non-IgAN) over the past 4 decades. Most countries show a progressive decrease. GN, glomerulonephritis.

We have used the term "frequency" for the various countries to enable us to compare the distribution of the various $\mathrm{GN}$ in these countries. We are aware that the term may not be appropriate for countries that have a national renal biopsy registry, which documents all or most of the renal biopsy data nationally and for these countries the term "prevalence" would be more appropriate. But the vast majority of countries do not have a national renal biopsy registry that documents all renal biopsies in the country. Certainly, in large countries such as China and India with their huge population, a truly national or single country wide registry would be a mammoth task and difficult to achieve. So, while we use the term frequency for all countries in this study, it is with the understanding that for many countries it would be more accurate to state that we are in fact comparing the "percentages" or "frequencies" of various categories of GN among these countries rather than the actual prevalence, which is only obtained when we have a national registry collecting all the biopsies throughout that particular country.

We acknowledge that the determination of the frequency of primary FSGS may be considered flawed as the ability to distinguish primary from genetic and secondary FSGS by light microscopy alone is doubtful [8]. In this paper, data on Primary FSGS are obtained from published reports of the host country.

Figures 1-4 show the various countries from among the countries where there are significant changing trends in the frequency for mesangial proliferative GN (decreasing frequency), IgA Nx (decreasing frequency), membranous GN (decreasing frequency), and FSGS (increasing frequency).

\section{Decreasing Frequency of Mesangial Proliferative GN and IgA Nx}

In this study, we have documented 4 decades of renal biopsy data, the 1 st decade shows IgA $\mathrm{Nx}$ as the most common GN with mesangial proliferative $\mathrm{GN}$ as the 2 nd most common. However, in Singapore, mesangial proliferative GN has been steadily decreasing as mentioned earlier, but IgA Nx, though the frequency is decreasing, still remains the most common GN. In general, countries in the Asian region with a high frequency of mesangial proliferative GN also have a high frequency of IgA Nx such as China [9], Hong Kong [10], Japan [11], Malaysia [12], Singapore [13-15, current], and Thailand [16] as shown in Table 4 . However, by the 4th decade, countries such as Australia [17], China [9], India [18], Japan [19], Singapore (current), Malaysia [12], and UK [20] have also documented decreasing frequency of mesangial proliferative GN over the past 4 decades as shown in (Fig. 1, Table 4).

However, in the 4th decade, a pivotal shift has occurred, many countries with increasing $\operatorname{IgA~Nx}$ are now seeing a dramatic decrease as in Australia [17], China [9]. Singapore (current), USA [5], UK [20], Italy [2] and India 


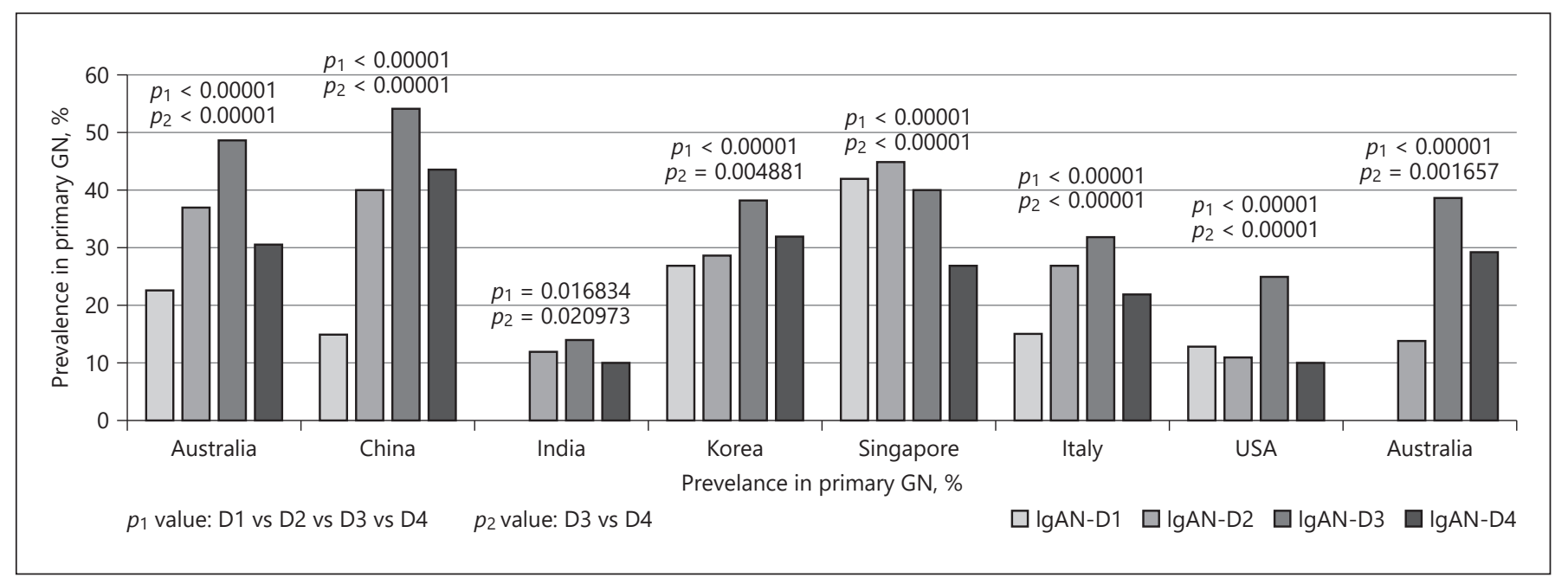

Fig. 2. Countries with decreasing trends for IgA $\mathrm{Nx}$ over the past 4 decades. In the first 3 decades, there was a progressive increase, but in the 4th decade, this had decreased. IgA Nx, IgA nephritis; GN, glomerulonephritis.

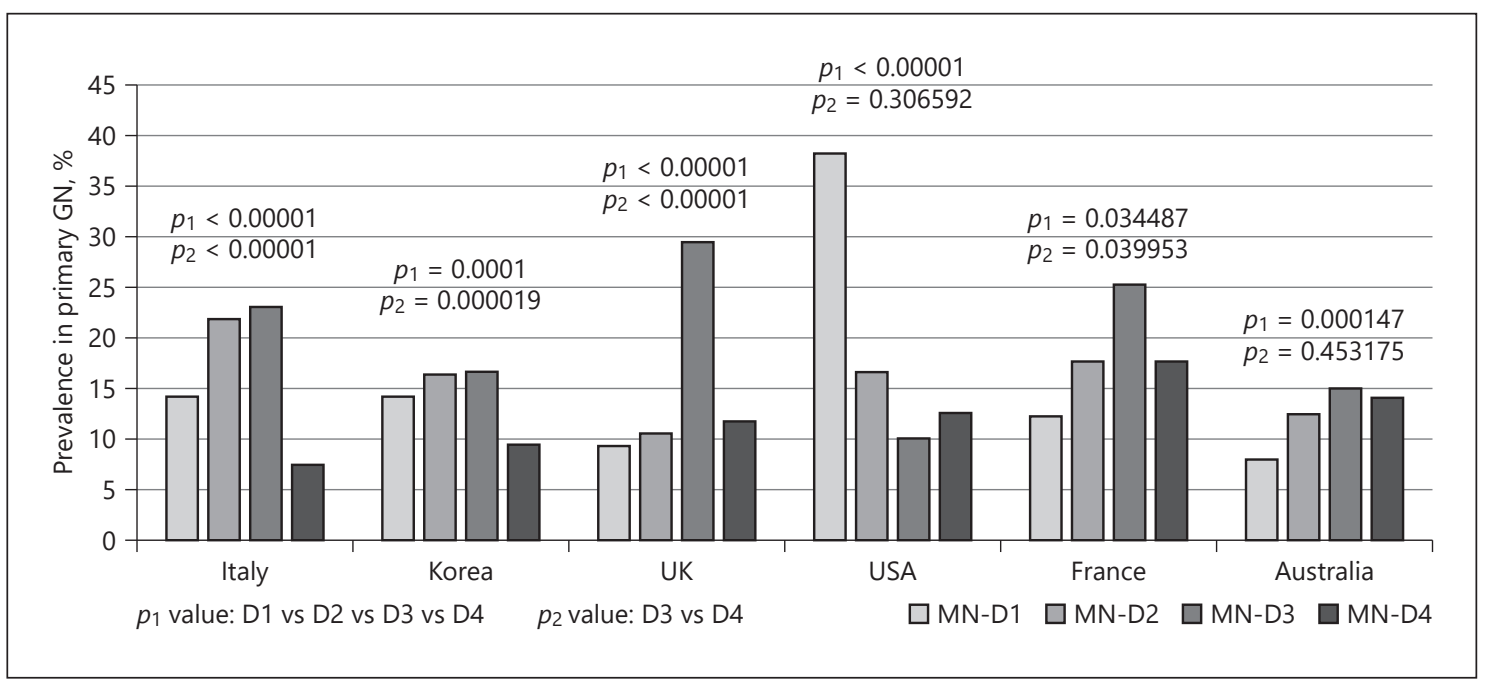

Fig. 3. Countries with decreasing trends for membranous nephropathy over the past 4 decades. For most countries, there was a progressive increasing trend, but in the $4^{\text {th }}$ decade, this has declined. GN, glomerulonephritis.

[18], and Korea [21], but in Japan [11] and Malaysia [12], the frequency of IgA Nx continues to increase in the 4th decade as seen in Figure 2 and Table 4 . This decrease in IgA $\mathrm{Nx}$ in many countries is the first pivotal shift in the changing trend of the renal biopsy pattern in these countries in the 4 th decade.

\section{Decreasing Frequency of Membranous GN}

Among Western countries in the preceding 3 decades before the 4th decade, Australia [22], France [7], Russia
[23], and the United Kingdom [24] and have also documented a rise in the frequency of membranous GN (Table 4 ). But in the 4th decade, though the frequency of membranous GN continues to increase in China [9] and Singapore (current; Fig. 3), in some countries, mainly in the West, such as Italy [2], UK [20], and USA [5], the frequency of membranous GN in the 4th decade is showing a declining trend as seen in Figure 3, but in the case of Australia, the difference in the decline between the 3rd and 4 th decades was not significant statistically $(p=0.45)$ 


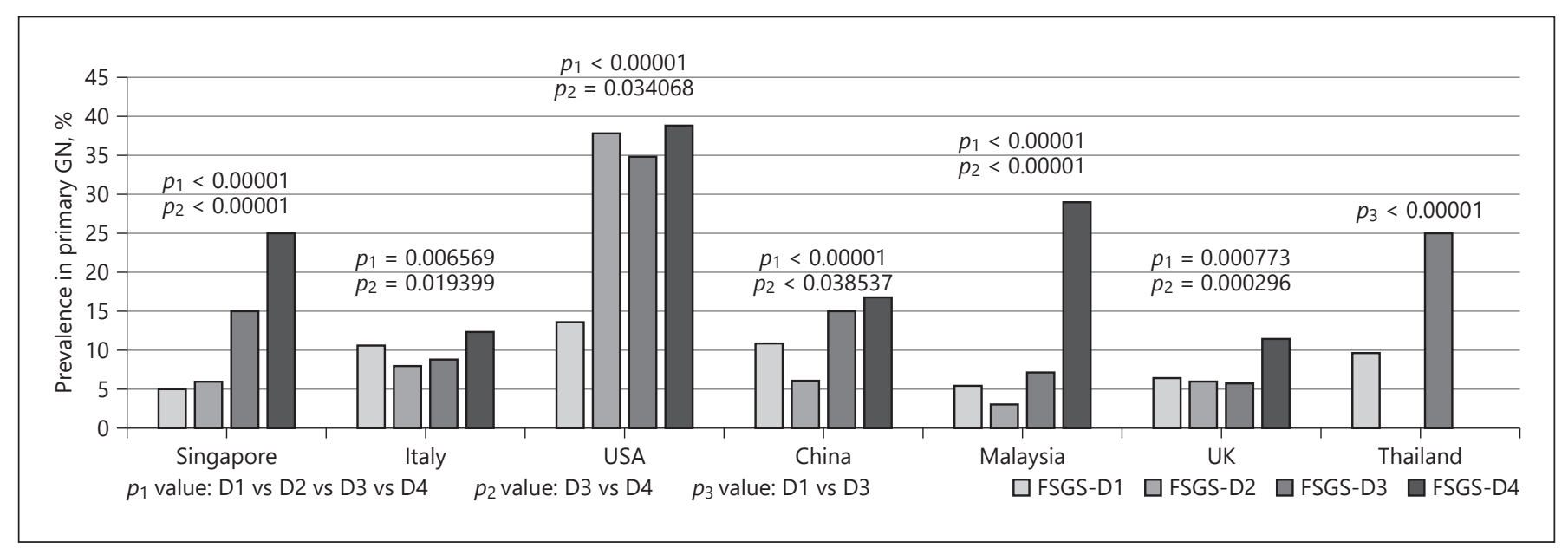

Fig. 4. Countries with increasing trends for focal segmental glomerulosclerosis over the past 4 decades. There is a progressive increase in all the countries. FSGS, focal sclerosing glomerulosclerosis; GN, glomerulonephritis.

[17]. This decreasing frequency of membranous GN in countries previously prevalent such as in UK, France, Italy, and USA (Table 4) is the second pivotal shift in the changing pattern of GN in these countries in the 4th decade. Singapore and China, with its still rising frequency of membranous GN, have not yet reached this pivotal point in the evolution of their renal biopsy pattern in this regard.

\section{The Rising Frequency of FSGS}

By the 3rd decade, there appears to be a wide spread increased frequency of FSGS in many countries such as Australia [22], India [25], Singapore [13, 14, current], Thailand [26], and USA [27, 28] as shown in Table 4 and Figure 4. But in the surrounding Asian countries such as China [29], Hong Kong [10], Japan [30], Korea [31], and Malaysia [32], the frequency of FSGS is still rather low (Table 4). In Singapore, in the 3rd decade, the frequency has risen dramatically together with Thailand [26] (Fig. 4). However, in certain countries in the West such as France [7] and Spain [33], the frequency of FSGS is also still relatively low (Table 4). Then in the 4 th decade, the frequency of FSGS goes on a meteoric rise in Singapore (current), Italy [2], USA [5], UK [20], China [9], and Malaysia [12], but in India [18] and Korea [21], there appears to be a significantly decreasing trend for frequency of FSGS between the $3 \mathrm{rd}$ and 4 th decades. The meteoric rise of FSGS in the many countries mentioned above indicates the third pivotal shift in the renal biopsy pattern of these countries.

Global Trend of Changing Pattern of GN

\section{Discussion}

\section{Factors Influencing the Pattern of GN}

Singapore is still in the phase of membranous GN plus increasing FSGS as in Malaysia, Thailand, and China. Membranous GN represents infective pathogenesis with smaller immune complexes deposition in the glomerular basement membrane as opposed to the olden days (1st decade), where the infective pathogenesis involved larger immune complexes with deposition in the mesangium giving rise to mesangial proliferative GN. The smaller immune complexes for membranous GN could be from viral or some other infections such as hepatitis. In a recent review from China [1], there was also a reported increase in membranous $\mathrm{GN}$, which was attributed to environmental exposure, industrialization, and lifestyle changes. It was suggested that industrialization was accompanied by environmental pollution, involving heavy metals and organic solvents. The authors believe that the high frequency of membranous GN was most likely associated with poor air quality with long-term exposure to high levels of PM 2.5 with increased risk of membranous GN [34].

As shown from the data on the 4 decades of renal biopsy in Singapore, one of the main factors that may play a role in the evolutionary pattern of $\mathrm{GN}$ in the population could be the socioeconomic change affecting the country. This is a trend reflecting the degree of development of the nation with a population living in less developed housing facilities in the early years with exposure to parasitic, bacterial, and other infective agents predisposing 
to mesangial proliferative GN consistent with the large size of the immune complexes trapped in the mesangium and hence invoking the immune reaction [13]. This would be true in Asian countries such as China [29, 35], Japan [30], Malaysia [36], and Thailand [26, 37] (Singapore [13] included), which have a high frequency of mesangial proliferative GN (Table 3). In some countries such as Japan [19], Korea [21], Malaysia [12], and Singapore $[15$, current], the frequency of mesangial proliferative GN is already decreasing in keeping with urbanization and better housing and other amenities in these countries. With subsequent resettlement of the people into improved living facilities with GN resulting from infections by parasites and bacteria slowly declining, the immune complexes being smaller now resulting more from viral and other infections, as well as other industrial allergens and environmental pollution. Possibly, these smaller immune complexes trapped in the basement membrane have led to the development of membranous GN [3]. Thus, a rising frequency of membranous $\mathrm{GN}$ is seen in these countries.

Even though primary GN is the commonest form of GN in Singapore, secondary GN is on the rise, and though lupus nephritis remains the commonest cause of secondary GN in clinical practice, diabetes is much more common because in practice many patients with diabetic nephropathy are not biopsied as nephrologists felt that a biopsy would not alter the management of their patients unlike patients with lupus nephritis, where a renal biopsy is necessary for diagnosis and management of the disease. In many countries, the prevalence of diabetes and obesity has steadily increased. We believe that this is related to the increasing number of patients with obesity and diabetes mellitus, a pattern representing the rising affluence in these countries where diabetes represents the changing lifestyle of fast food and unhealthy diets predisposing to obesity and diabetes [38]. This same trend has also been observed in Singapore [3] and the surrounding countries such as Malaysia [39], Taiwan [40, 41], India [42], and Australia [17, 43], where diabetes is the commonest secondary GN and also the commonest cause of end-stage renal failure.

In terms of allergens and pollutants as causation of GN in Singapore, minimal change disease is the commonest cause of the nephrotic syndrome (32\%) followed by FSGS (29.3\%) the next commonest cause, perhaps the result of Singapore having the highest percentage of tree space (23\%) planted in its land space, numbering among the top 10 cities in the world with the most green space from trees planted [44]. With increased greenery, perhaps there is also increased exposure to pollen and hay fever induced by allergens. Hence, in the 4th decade, the age of artificial intelligence, we live in a new world of smart global villages with the inhabitants exposed to allergens and pollutants, products of industrialization and civilization, in a world held to ransom by $\mathrm{CO}_{2}$ emission resulting from climatic change [45]. And for the super economies in the Western world such as the United States and the United Kingdom, these have gone past the phase of increasing membranous $\mathrm{GN}$ and together with the decline in IgA Nx and membranous GN, they are now faced with the dilemma of ever increasing FSGS, a disease reflecting the changing era of the digital age.

\section{Conclusion}

We can conclude that with urbanization and socioeconomic changes and less exposure to parasitic and other infestations, Singapore's biopsy pattern is tending toward that of more developed countries. Antigenic exposure due to lifestyle changes, environmental and industrial allergens, as well as dietary factors may be significant contributory factors, which predispose to the rising frequency of membranous GN and FSGS. This trend is true for the surrounding Asian countries including China as well in comparison to the more advanced super economies such as USA and UK, where many are faced with the rising trend of FSGS with the decline in membranous GN.

\section{Acknowledgments}

This is an academic study supported by Singhealth Cluster with Institutional Review Board (IRB) approval - CIRB Ref No 3147 E, and study protocol has been approved by the Institution's IRB committee on human research and conform to institutional standards.

We would like to thank $\mathrm{M} / \mathrm{s}$ Connie Lew for secretarial and administrative assistance.

\section{Statement of Ethics}

The study protocol has been approved by the Institution's IRB committee on human research and conforms to institutional standards.

\section{Disclosure Statement}

We declare that there are no conflicts of interest pertaining to this work, and we have no ethical conflicts to disclose. 


\section{Author Contributions}

K.T.W. is the lead as well as corresponding author who gathered the data and wrote the manuscript. C.M.C. read and corrected the manuscript. C.L. and J.C. read and wrote part of the manuscript. Y.M.C. read and prepared the tables. E.W.L.T. read and prepared figures and references and assisted in submission of manuscript. I.M. and J.L.K. read and corrected part of the manuscript. A.H.L.L. and P.H.T. read the renal biopsies. H.L.C., H.K.T., K.S.W., G.S.L.L., and E.L. read and corrected the manuscript. M.F. head of department who read, corrected, and vetted the paper.

\section{References}

1 Hou JH, Zhu HX, Zhou ML, Le WB, Zeng CH, Liang SS, Xu F, Liang DD, Shao SJ, Liu Y, Liu ZH: Changes in the Spectrum of Kidney Diseases: An Analysis of 40,759 Biopsy-Proven Cases from 2003 to 2014 in China. Kidney diseases (Basel). 2018 Feb;4(1):10-9.

2 Zaza G, Bernich P, Lupo A; 'Triveneto' Register of Renal Biopsies (TVRRB). Renal biopsy in chronic kidney disease: lessons from a large Italian registry. Am J Nephrol. 2013;37(3): 255-63.

3 Singapore Renal Registry Annual Report 2016.

4 Jacob C. Renal Disease: Classification and Atlas of glomerular diseases. New York: IgakuShoin; 1987.

5 Sim JJ, Batech M, Hever A, Harrison TN, Avelar T, Kanter MH, et al. Distribution of Biopsy-Proven Presumed Primary Glomerulonephropathies in 2000-2011 Among a Racially and Ethnically Diverse US Population. Am J Kidney Dis. 2016 Oct;68(4):533-44.

6 Arias LF, Henao J, Giraldo RD, Carvajal N, Rodelo J, Arbeláez M. Glomerular diseases in a Hispanic population: review of a regional renal biopsy database. Sao Paulo Med J. 2009; 127(3):140-4.

7 Simon P, Ramee MP, Boulahrouz R, Stanescu C, Charasse C, Ang KS, et al. Epidemiologic data of primary glomerular diseases in western France. Kidney Int. 2004 Sep;66(3):905-8.

8 Hommos MS, De Vriese AS, Alexander MP, Sethi S, Vaughan L, Zand L, et al. The Incidence of Primary vs Secondary Focal Segmental Glomerulosclerosis: A Clinicopathologic Study. Mayo Clin Proc. 2017 Dec;92(12): 1772-81.

9 Xu X, Ning Y, Shang W, Li M, Ku M, Li Q, et al. Analysis of 4931 renal biopsy data in central China from 1994 to 2014. Ren Fail. 2016 Aug;38(7):1021-30.

10 Chan KW, Chan TM, Cheng IK: Clinical and pathological characteristics of patients with glomerular diseases at a university teaching hospital: 5-year prospective review. Hong Kong Med J. 1999 Sep;5(3):240-4.

11 Sugiyama H, Yokoyama H, Sato H, Saito T, Kohda Y, Nishi S, et al.; Committee for Standardization of Renal Pathological Diagnosis and Working Group for Renal Biopsy Database, Japanese Society of Nephrology, Tokyo, Japan. Japan Renal Biopsy Registry: the first nationwide, web-based, and prospective registry system of renal biopsies in Japan. Clin Exp Nephrol. 2011 Aug;15(4):493-503.
12 Sunita Bavanandan LSK: 5th Report Of The Malaysian Registry Of Renal Biopsy. Chapter 2: Primary Glomerulonephritis., pp 19-51.

13 Woo KT, Chiang GS, Edmondson RP, Wu AY, Lee EJ, Pwee HS, et al. Glomerulonephritis in Singapore: an overview. Ann Acad Med Singapore. 1986 Jan;15(1):20-31.

14 Woo KT, Chiang GS, Pall A, Tan PH, Lau YK, Chin YM. The changing pattern of glomerulonephritis in Singapore over the past two decades. Clin Nephrol. 1999 Aug;52(2):96-102.

15 Woo KT, Chan CM, Mooi CY, -L-Choong H, Tan HK, Foo M, et al. The changing pattern of primary glomerulonephritis in Singapore and other countries over the past 3 decades. Clin Nephrol. 2010 Nov;74(5):372-83.

16 Kanjanabuch T, Kittikovit W, Lewsuwan S, Leelahavanichkul A, Avihingsanon Y, Praditpornsilpa K, et al. Etiologies of glomerular diseases in Thailand: a renal biopsy study of 506 cases. J Med Assoc Thai. 2005 Sep; 88 Suppl 4:S305-11.

17 Jegatheesan D, Nath K, Reyaldeen R, Sivasuthan G, John GT, Francis L, et al. Epidemiology of biopsy-proven glomerulonephritis in Queensland adults. Nephrology (Carlton). 2016 Jan;21(1):28-34.

18 Golay V, Trivedi M, Abraham A, Roychowdhary A, Pandey R. The spectrum of glomerular diseases in a single center: A clinicopathological correlation. Indian J Nephrol. 2013 May;23(3):168-75.

19 Yokoyama H, Sugiyama H, Narita I, Saito T, Yamagata K, Nishio S, et al. Outcomes of primary nephrotic syndrome in elderly Japanese: retrospective analysis of the Japan Renal Biopsy Registry (J-RBR). Clin Exp Nephrol. 2015 Jun;19(3):496-505.

20 The Scottish Renal Registry Report 2016, pp 1-95.

21 Shin HS, Cho DH, Kang SK, Kim HJ, Kim SY, Yang JW, et al. Patterns of renal disease in South Korea: a 20 -year review of a single-center renal biopsy database. Ren Fail. 2017 Nov; 39(1):540-6.

22 Briganti EM, Dowling J, Finlay M, Hill PA, Jones CL, Kincaid-Smith PS, et al. The incidence of biopsy-proven glomerulonephritis in Australia. Nephrol Dial Transplant. 2001 Jul;16(7):1364-7.

23 Dzhanaliev BR, Varshavskiǔ VA, Laurinavichus AA. [Primary glomerulopathies: incidence, dynamics and clinical manifestations of morphological variants]. Arkh Patol. 2002 Mar-Apr;64(2):32-5.
24 Hanko JB, Mullan RN, O’Rourke DM, McNamee PT, Maxwell AP, Courtney AE. The changing pattern of adult primary glomerular disease. Nephrol Dial Transplant. 2009 Oct; 24(10):3050-4.

25 Narasimhan B, Chacko B, John GT, Korula A, Kirubakaran MG, Jacob CK. Characterization of kidney lesions in Indian adults: towards a renal biopsy registry. J Nephrol. 2006 MarApr;19(2):205-10.

26 Parichatikanond P, Chawanasuntorapoj R, Shayakul C, Choensuchon B, Vasuvattakul S, Vareesangthip K, et al. An analysis of 3,555 cases of renal biopsy in Thailand. J Med Assoc Thai. 2006 Aug;89 Suppl 2:S106-11.

27 Dragovic D, Rosenstock JL, Wahl SJ, Panagopoulos G, DeVita MV, Michelis MF. Increasing incidence of focal segmental glomerulosclerosis and an examination of demographic patterns. Clin Nephrol. 2005 Jan;63(1):1-7.

28 Swaminathan S, Leung N, Lager DJ, Melton LJ 3rd, Bergstralh EJ, Rohlinger A, et al. Changing incidence of glomerular disease in Olmsted County, Minnesota: a 30-year renal biopsy study. Clin J Am Soc Nephrol. 2006 May;1(3):483-7.

29 Li LS, Liu ZH. Epidemiologic data of renal diseases from a single unit in China: analysis based on 13,519 renal biopsies. Kidney Int. 2004 Sep;66(3):920-3.

30 Honma M, Toyoda M, Umezono T, Kato M, Kobayashi K, Miyauchi M, et al. An investigation of 2,093 renal biopsies performed at Tokai University Hospital between 1976 and 2000. Clin Nephrol. 2008 Jan;69(1):18-23.

31 Choi IJ, Jeong HJ, Han DS, Lee JS, Choi KH, Kang SW, et al. An analysis of 4,514 cases of renal biopsy in Korea. Yonsei Med J. 2001 Apr;42(2):247-54

32 Looi LM. The pattern of renal disease in Malaysia. Malays J Pathol. 1994 Jun;16(1):19-21.

33 Rivera F, López-Gómez JM, Pérez-García R; Spanish Registry of Glomerulonephritis. Clinicopathologic correlations of renal pathology in Spain. Kidney Int. 2004 Sep;66(3): 898-904.

34 Xu X, Wang G, Chen N, Lu T, Nie S, Xu G, et al. Long-Term Exposure to Air Pollution and Increased Risk of Membranous Nephropathy in China. J Am Soc Nephrol. 2016 Dec;27(12): 3739-46.

35 Chen H, Tang Z, Zeng C, Hu W, Wang Q, Yu $\mathrm{Y}$, et al. Pathological demography of native patients in a nephrology center in China. Chin Med J (Engl). 2003 Sep;116(9):1377-81. 
36 Prathap K, Looi LM. Morphological patterns of glomerular disease in renal biopsies from 1000 Malaysian patients. Ann Acad Med Singapore. 1982 Jan;11(1):52-6.

37 Boonpucknavig V BS: Glomerular diseases in Thailand: incidence, histology, immunopathology of renal biopsies in 500 cases. Proc of the Asian.

38 D'Agati VD, Chagnac A, de Vries AP, Levi M, Porrini E, Herman-Edelstein M, et al. Obesity-related glomerulopathy: clinical and pathologic characteristics and pathogenesis. Nat Rev Nephrol. 2016 Aug;12(8):453-71.

39 23rd Report of the Malaysian Dialysis and Transplant Registry 2015

40 Chiu HF, Chen HC, Lu KC, Shu KH; Taiwan Society of Nephrology. Distribution of glomerular diseases in Taiwan: preliminary report of National Renal Biopsy Registry-publication on behalf of Taiwan Society of Nephrology. BMC Nephrol. 2018 Jan;19(1):6.

41 Hwang SJ, Tsai JC, Chen HC. Epidemiology, impact and preventive care of chronic kidney disease in Taiwan. Nephrology (Carlton). 2010 Jun;15 Suppl 2:3-9.

42 Jha V. Current status of end-stage renal disease care in India and Pakistan. Kidney Int Suppl. 2013;3(2):157-60.

43 Australian Bureau of Statistics. Australian Health Survey: Biomedical Results for Chronic Diseases.

44 Kolczak A. This City Aims to Be the World's Greenest, National Geographic, 2017, 2018, Website link: https://www.nationalgeographic.com/environment/urbanexpeditions/ greenbuildings/green-urban-landscape-cities-Singapore/. Accessed date: 21 Sep 2018.

45 Barraclough KA, Blashki GA, Holt SG, Agar JW. Climate change and kidney diseasethreats and opportunities. Kidney Int. 2017 Sep;92(3):526-30.

46 Clarkson AR, Seymour AE, Meadows R. Frequency and Morbidity of Renal Disease in an Australian Community.; in Oshima K YY, Hatano M (ed): Proc 1st Asian Pacific Cong Nephrol. Tokyo, Japan, Asian Pacific Society Nephrol, 1979.

47 Painter D, Clouston D, Ahn E, Kirwan P, Ledoux F, Tivollier JM, et al. The pattern of glomerular disease in New Caledonia: preliminary findings. Pathology. 1996 Jan;28(1): $32-5$.

48 Okpechi IG, Ameh OI, Bello AK, Ronco P, Swanepoel CR, Kengne AP. Epidemiology of Histologically Proven Glomerulonephritis in Africa: A Systematic Review and Meta-Analysis. PLoS One. 2016 Mar;11(3):e0152203.

49 Bahiense-Oliveira M, Saldanha LB, Mota EL, Penna DO, Barros RT, Romão-Junior JE. Primary glomerular diseases in Brazil (19791999): is the frequency of focal and segmental glomerulosclerosis increasing? Clin Nephrol. $2004 \mathrm{Feb} ; 61(2): 90-7$.
50 Mazzarolo Cruz HM, Cruz J, Silva AL Jr, Saldanha LB, de Oliveira Penna D. Prevalence of adult primary glomerular diseases: retrospective analysis of 206 kidney biopsies (19901993). Rev Hosp Clin Fac Med Sao Paulo. 1996 Jan-Feb;51(1):3-6.

51 Malafronte P, Mastroianni-Kirsztajn G, Betônico GN, Romão JE Jr, Alves MA, Carvalho MF, et al. Paulista Registry of glomerulonephritis: 5-year data report. Nephrol Dial Transplant. 2006 Nov;21(11):3098-105.

52 Polito MG, de Moura LA, Kirsztajn GM. An overview on frequency of renal biopsy diagnosis in Brazil: clinical and pathological patterns based on 9,617 native kidney biopsies. Nephrol Dial Transplant. 2010 Feb;25(2): 490-6.

53 LS L. Renal Diseases in China: an Overview; in Woo KT WA, Lim CH (ed): >Proc 3rd Asian Pacific Congress of Nephrology. Singapore, 1986, pp 292-296.

54 Zhou FD, Zhao MH, Zou WZ, Liu G, Wang $\mathrm{H}$. The changing spectrum of primary glomerular diseases within 15 years: a survey of 3331 patients in a single Chinese centre. Nephrol Dial Transplant. 2009 Mar;24(3): 870-6.

55 Rychlík I, Jancová E, Tesar V, Kolsky A, Lácha J, Stejskal J, et al. The Czech registry of renal biopsies. Occurrence of renal diseases in the years 1994-2000. Nephrol Dial Transplant. 2004 Dec;19(12):3040-9.

56 Maixnerova D, Jancova E, Skibova J, Rysava R, Rychlik I, Viklicky O, et al. Nationwide biopsy survey of renal diseases in the Czech Republic during the years 1994-2011. J Nephrol. 2015 Feb;28(1):39-49.

57 Heaf J, Løkkegaard H, Larsen S. The epidemiology and prognosis of glomerulonephritis in Denmark 1985-1997. Nephrol Dial Transplant. 1999 Aug;14(8):1889-97.

58 Simon P, Ramee MP, Ang KS, Cam G. [Course of the annual incidence of primary glomerulopathies in a population of 400,000 inhabitants over a 10-year period (1976-1985)]. Nephrologie. 1986;7(5):185-9.

59 Simon P, Ramée MP, Autuly V, Laruelle E, Charasse C, Cam G, et al. Epidemiology of primary glomerular diseases in a French region. Variations according to period and age. Kidney Int. 1994 Oct;46(4):1192-8.

$60 \mathrm{Ng} \mathrm{WL}$. Primary Glomerular Disease in Adult Chinese in Hong Kong.; in K Oshima TT (ed): Proc 3rd Colloquium in Nephrology. Tokyo, Sasaki Printing and Publishing Co Ltd, 1979, pp 65-68.

61 Chugh KS, Sharma BK, Datta BN. Thomas Mathew M, Singhal PC: Pattern of Renal Disease in North India. Ann Acad Med Singapore. 1975;2:41-3.

62 Balakrishnan N, John GT, Korula A, Visalakshi J, Talaulikar GS, Thomas PP, Jacob CK. Spectrum of biopsy proven renal disease and changing trends at a tropical tertiary care centre 1990 - 2001. Indian J Nephrol. 2003;13(1):29-35.
63 Schena FP; The Italian Group of Renal Immunopathology. Survey of the Italian Registry of Renal Biopsies. Frequency of the renal diseases for 7 consecutive years. Nephrol Dial Transplant. 1997 Mar;12(3):418-26.

64 Stratta P, Segoloni GP, Canavese C, Sandri L, Mazzucco G, Roccatello D, et al. Incidence of biopsy-proven primary glomerulonephritis in an Italian province. Am J Kidney Dis. 1996 May;27(5):631-9.

65 Gesualdo L, Di Palma AM, Morrone LF, Strippoli GF, Schena FP; Italian Immunopathology Group, Italian Society of Nephrology. The Italian experience of the national registry of renal biopsies. Kidney Int. 2004 Sep;66(3): 890-4.

66 Panichi V, Pasquariello A, Innocenti M, Meola M, Mantuano E, Beati S, et al. The Pisa experience of renal biopsies, 1977-2005. J Nephrol. 2007 May-Jun;20(3):329-35.

67 Research Group on Progressive Chronic Renal Disease. Nationwide and long-term survey of primary glomerulonephritis in Japan as observed in 1,850 biopsied cases. Nephron. 1999;82(3):205-13.

68 Choi IJ, Jeong HJ, Han DS, Lee JS, Lee HY, Kim PK. An analysis of 2361 cases of renal biopsy in Korea. Yonsei Med J. 1991 Mar; 32(1):9-15.

69 Chang JH, Kim DK, Kim HW, Park SY, Yoo TH, Kim BS, et al. Changing prevalence of glomerular diseases in Korean adults: a review of 20 years of experience. Nephrol Dial Transplant. 2009 Aug;24(8):2406-10.

70 Khoo JJ. Renal biopsies in Johor: a 7-year study. Malays J Pathol. 2001 Dec;23(2):101-4.

71 Serov VV, Varshavsky VA, Schill H, Nizze H. [Incidence of glomerular diseases in kidney biopsy materials using WHO classification]. Zentralbl Allg Pathol. 1986;132(5-6):471-5.

72 Rivera F, López-Gómez JM, Pérez-García R; Spsnish Registry of Glomerulonephritis. Frequency of renal pathology in Spain 19941999. Nephrol Dial Transplant. 2002 Sep; 17(9):1594-602.

73 Kuang-Chin Hsiao JD. Shen-Wen Wu TenYear Registry of Native Kidney Biopsy from a Single Center in Taichung. Acta Neurol (Napoli). 2012;26:68-73.

74 JS C. Clinicopathological Correlation in Glomerulonephritis: Problems and Limitations. Proc 1st Colloquium in Nephrology. Singapore. Ann Acad Med Singapore. 1975;4:4551.

75 Davison AM. The United Kingdom Medical Research Council's glomerulonephritis registry. Contrib Nephrol. 1985;48:24-35.

76 Braden GL, Mulhern JG, O'Shea MH, Nash SV, Ucci AA Jr, Germain MJ. Changing incidence of glomerular diseases in adults. Am J Kidney Dis. 2000 May;35(5):878-83. 